\title{
History of contemporary self-image
}

\author{
Misbah Islam ${ }^{\mathrm{a}, 1, *}$, Natalie Samynadin ${ }^{\mathrm{b}, 2}$ \\ a Nanjing University of the Arts, 74 Beijing West Road, Nanjing, Jiangsu 210013, People Republic of China \\ ${ }^{a}$ University of Seychelles, Anse Royale, Victoria, Mahé, 1348, Seychelles \\ ${ }^{1}$ CreativeCamp@qq.com*; ${ }^{2}$ nataliemiche180@yahoo.com \\ * corresponding author
}

ARTICLE INFO

Article history

Received 2020-06-24

Revised 2020-06-28

Accepted 2020-07-01

\section{ABSTRACT}

This paper aims to describe how the development of the art of selfie photography in the world. This research is library research; the author seeks various reading materials that support the acquisition of data. The reading article is a book and research results published in libraries and online. This study shows that in history, selfies do not only talk about narcissism but have a strong cultural philosophy.
Keywords

Self-Image

History

Aesthetics

Portrait

Photography
This is an open access article under the CC-BY-SA license.

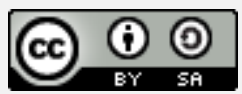

\section{Introduction}

Since the earlier history of humanity Self-image always get immense attention as the aesthetic sense of human understood evolution. The historical evidence of surviving self-images has evolved from eminent Rome and Greek civilizations as we may expect but is traced back to historic Egypt; An ancient society that entirely focused on the worship of gods and their representatives on this planet. The concept of self-image evolved throughout this long period. It got a significant breakthrough when the traditional camera was invented and industrialized. Again, self-image gained phenomenal prominence and growth when smartphones and the internet have connected with advanced communication networks. Contemporary self-image has achieved many dynamic properties as it exists in the era of modern society and evolved within the progression of new technologies.

During the venture of exploring the self-images in the historical and current scenario, I found its strong linkage with our internal self (identity), as well as the complexities of the digital and visual culture of contemporary society. I found that all these elements are interconnected with the fibers of all these elements of society, culture, arts, and other elements of our social ecology, which creates a sophisticated beauty, and I am lost into it. According to McLuhan's media theory, a self-portrait's cultural value depends on the sociological scenario, where it has come into being.

The self-portrait in the modern network culture is a digital image of a smartphone, distributed through social-networking internets. The creation of a smartphone self-portrait is an art or craft which is neither highly praised nor valued in a societal environment where methods of production and distribution are broadly accessible and no longer a unique piece of creative skills. Nevertheless, this society places excellent social and cultural importance of the culture of celebrities and influential peoples. I find myself lost in self-portraiture and phonemicization of SELF during this exploration; so, I indulge in this study about this act of self-representation and the motivations behind it. 
Self is still a complex phenomenon; I have hardly scratched the self-representation realm's surface. I will remain fascinated by the representation of identity; this phenomenon allows me to continue to explore more about self, which exists in a society based on contemporary technological advancement. In this attempt, I am going to find the roots in ancient history and culture and elaborate its significance in current society. We will dig down the history from ancient Egyptian and Greek civilizations mythological but significant self-images to today's contemporary Selfies [1]

The historical evidence of surviving self-images has evolved from eminent Rome and Greek civilizations as we may expect but is traced back to historic Egypt; An ancient society that entirely focuses the worship of gods and their representatives on this planet. During the earlier period of history, images were mainly used for communicating, and most important events were recorded, and also, the notable personalities engage in them; extensive portraits were associated with pharaohs, their Gods and Deities. Through generic representations of their professions, laborers and people from lower-status were displayed. Unless they were of supreme importance, it was a sporadic display of any other class of society. One of the first men to produce a self-portrait was Bak, a sculptor to pharaoh Akhenaten. He successfully enhanced his position from an ordinary laborer to an Art-Creator by carving his portrait on a stela, a respected figure in the pharaoh [2]. Between 1353 and 1336 BC, Akhenaten ruled Egypt. He imposed his supremacy to Aten's glory, The sun disk, also renew the concurrence of their traditions on the national level.

In honor of Aten, who made life possible, he wanted to be surrounded by expressive and natural visuals [3]. He found it in newly discovered curved sculpture and carved family panoramas [4]. In this regard, Akhenaten was willing to create artwork that engraving round another of Bak's portrait reveals "techniques of making Art," possibly signifying as a source of inspiration in terms of making new kind of illustration, instructed by the pharaoh. The confident presence of self-portrait stelae indicates that Bak's work was widely admired that his status was almost equal to that of Akhenaten, his family, and their God. In ancient Egypt, the practice of self-portrait was different from that in the European Renaissance, founded on humanism's values.

The concept of individualism in the context of self-image is comparatively new as it was in renaissance-era, which was assumed the Only creator is God as in the Middle Ages. Celebration of the Human's creative ability encouraged creators to consider themselves as an artist and Human, themes instead of subjected as religion [5].

The idea of Humanistic Ideology denotes that the current theory of society and theories from the 15 th to the 17 th century. In the popularity of pagan classics, there was a resurgence, these both engendered and increased interest in ideas of secularism, enjoyment of worldly pleasures. Above all, this idea reinforced the declaration of individual expression and personal autonomy [6]. The negative impacts of Bubonic Plague disheartened their believers. There was an influx of economic growth due to trade in areas governed by more about wealth than Christianity. That idea brings uncertainty to religion's influence, and humanism has become a fascinating option. It put Renaissance artists between two worlds; the Christian order created, and humanism's evolving liberation. Both would play a significant role in self-portrait's evolution [7].

\section{Theorical Framework}

\subsection{Self-Reflection as A Self-Image}

A mirror is a critical tool in self-portraits development, enabling artists to examine and copy their reflection. Mirrors like stagnant water, glazed rock, and mate have existed since ancient times [8]. Most hypotheses about the emergence of self-image in the Renaissance mention the manufacture of smooth Venetian glass Mirrors for a cause. Still, until the late seventeenth century, they were tiny and expensive. Before that, many artists used the metal-backed convex glass mirrors-a technique established in the Middle Ages [9].

Throughout religious texts on self-improvement, the idea of the mirror was also favored; according to concepts throughout St. Augustine's writings, every living thing represents the GOD and its spirit. The level of transparency of the mirror depends on the ' chain of being ' on the scale; in I Corinthians 13:12 Virgin Mary is considered a "clean glass-mirror [9]. Looking into the glassmirror, either it's real or metaphorical, is considered a prospect to recognize one's virtues, so. One 
can make self-improvement, be nearer to God. The same kind of religious teachings can be found in the preaching of Plato and Socrates, about the mirror as a method of self-understanding.

Throughout history, Mirrors were invented to enable man to self-awareness, resulting in gaining several benefits from it: firstly, self-knowledge; second, self-knowledge in many dimensions. The beautiful person, not necessarily to be legendary. The ugly person, to realize this virtue must compensate for what he lacks in physical appearance.

Always a young person, still remembered by the youth of him, considered to be the time of real deeds and bold acts, the older man must feel about the thought related to end-of-life. That's why nature has given us the chance to see each other. A transparent source of water or a glazed rock reflects its image to every individual [10]. The Seneca claimed that there was a rational interpretation of physical experience. Glasses and mirrors were promoted as apparatuses of observing the self with these two theories. It wasn't until the emergence of humanism that selfportrait will be famous in that era.

\subsection{Self-Image and the Renaissance Era}

Started in the late 1300s in Florence, the Italian Renaissance was the time of a significant cultural change. Florence was ruled under democracy, not by empire; there were so many other European small countries, which permitted wealthy traders and further people to gain prominence, such as the Medici family. Because of this economic system, Florence's leading figures have the resources to contract wealthy works of art, which would be a homage to their richness. With the growing influence of humanism, this rise in patronage formed a lively and vivid environment for artists of that time [11]. Meanwhile, Italy's ideas were not spread to the north side until around the 1500s. At that time, other Europe already had their cultural Renaissance.

An eye for details, self-expression, and other exemplary method and color created those artworks as a desired of, especially those of renowned artist Jan van Eyck. In the religious commissioned artwork of Van Eyck, especially Ghent Altarpiece, that's considered a significant landmark to Western Renaissance art's" modern realism [12]. Van Eyck also recognized by promoting Oil Paint usage, producing a vivid medium that prominent physical features like skin, hair, and cloths in his paintings. His painting "portrait of the man in Turban" was believed to be the first self-portrait in the west since ancient times, although there is doubt about whether the topic was Van Eyck since there was no depiction to demonstrate it. On the surrounding picture, however, there is a faux-gravure pointing to personal expression.

"As I can" was written on the frame in Greek letter, and considered be the signature sentence of van Eyck, It is stated as a trick on Text, signifying its technological ability, I do the best what I can" also its nickname with a beautiful expression" As only Ayck Can" [13]. Van Eyck's self-portraiture, as a masterpiece of Renaissance art, supported artists ' rising status in the 15th century. As one of the most sought-after artists of his country, German painter Albrecht Durer also gained attention. From a young age, Durer developed many self-portraits, either as physical experiments or as gifts to his friends [14].

Durer was shocked by the special status awarded to the artists when he traveled to Italy in 1494 to research their art style. He wrote to his friend in a letter: How will I freeze by this heat! I'm a nobleman here, but a bloodsucker at home [15]. His self-portrait took a new course when he returned to Germany. He started to depict himself in glamorous, luxurious clothing and stiff poses, inspired by the social status of Italian painters. Durer completed a self-portrait in 1500 that violated contemporary art's constraints. The way Durer has put himself is the most confrontational aspect of this work. Addressing his audience with eyes, it is portrayed by a style reserved absolutely for Jesus Christ photographs. Durer makes many references to an artist's instruments with this blatant assertion of strength and divinity. His right hand's prominence alludes to a painter's working hand, and the positioning of eye-level golden inscriptions directs the audience [16]. Durer introduces himself as the artist-creator with this self-portrait, a divine picture-maker just as God made man in his image. Alternatively, Durer takes his place beyond a tribute to God. As art historian Joseph Koerner says, "Dürer's is not anything we see in a Dürer" [17]. The Self-portraiture in this section are connected with a common theme of self-representation in the Art-history. Each artwork was created by the motivation that "want to portray the artist in a high-status position. In the beginning, this status was connected to religious hierarchy, later with the advent of humanism; it came to be an 
exploration of self-exploration and self-worth. It evolved during the Renaissance to show the artist's masterful imagination and significance to society.

Later I was revealed that it is not only for self-portraits but also for contemporary selfies; this as an underlying theme. Even if the social perspective has altered and media production has disconnected the network-culture, this basic desire for publicity and influence will remain the main point in the self-centered portrait of the contemporary era.

\section{Method}

This manuscript is the result of library research is a type of qualitative research that is generally carried out by not plunging into the field in search of data sources. Literature research can also be interpreted as research carried out based only on written works, including research results that have been or have not been published.

Literature research is a method of searching, collecting, and analyzing data sources to be processed and presented in the form of a Literature Research report [18]. The methods used in this library research include; (1) Keyword search: Search for relevant keywords in catalogs, indexes, search engines, and full-text sources. This is useful for narrowing the search to a specific subject title and finding sources that are not captured under the relevant subject heading. To effectively search a database, start by searching for Keywords, find relevant records, and then find a suitable Subject Title. In the search engine, include many keywords to narrow the search and carefully evaluate what you see.

(2) Subject search: Subject titles (sometimes called Descriptors) are special terms or phrases that are used consistently by online or print indexes to describe books or journal articles. This applies to library catalogs as well as many other library databases. (3) Search for the latest books and scientific reports: In directories and databases, sort by the newest date and look for books from scientific magazines and articles from scientific journals - the further the source, the more references, and the latest quotes.

(4) Search for citations in scientific sources: Track references, footnotes, endnotes, quotes, etc. in relevant reading. Search for a particular book or journal in the library catalog. This technique helps you become part of a scientific conversation about a specific topic. Search through published bibliographies (including sets of footnotes in relevant subject documents) [19]. References published on certain subjects often include sources that were missed through other types of searches. The Bibliography is the subject title in the catalog, so a quest guided by Bibliography as your subject and topic as a keyword will help you find it.

Search through people's sources (whether through verbal contact, email, etc.). People are often more willing to help than you think. Such people are, for example, professors or librarians with relevant knowledge. Systematic exploration, especially full-text sources arranged in groupings of subjects that can be predicted. The library organizes books by topic, with similar books kept together. Exploring stacks is an excellent way to find similar books; however, in large libraries, some books are not in the main stack, so use the catalog.

\section{Results and Discussion}

\subsection{Self-Portraiture and Photography}

Since the 17th century, the Camera Obscura had been used by artists and was modified by Nicephore Niepce to produce the first portrait, just after the discovery of photosensitive paper [20]. $\mathrm{He}$ continued his experiments of affixing the images, later started working with Luis DaguerreHe was doing successful experiments called the daguerreotype, just four years after the death of Niepce. Unless the original was re-photographed, a daguerreotype was unable to replicate similar to the creation of artworks. William Henry Fox Talbot was another prominent figure in the development of photography, who was trying to master these techniques, by using negative photography image. $\mathrm{He}$ gets to know that Photographic images are "Brushes of God" [21]. After several copies, re-copying from this process, it deteriorated the image quality. Such early photographic experiments on the basis, which our current capturing technology is based. While photography is lightweight, accurate, and perfect, there is necessarily a combination of incident, detail, aesthetic, and most of the Human 
Elements. That's likely because it's visual arts blends very well and it was not used just as a scientific resource.

Since the 1840s, artists have created "illegitimate offspring of the camera and the brush" by capturing and replicating arrangements from Arts through the lenses [21]. Delacroix started to use photos as a foundation for his paintings, enabling a previously unseen level of detail. It has been a healthy development, and photography is now intimately connected to Arts [22]. Over time, the technology of photography continues to revolutionize all how photographs could be made. The development of celluloid film-roll has played a significant role in creating an affordable and compact film camera [23]. There was a groundbreaking development of the world's first digital camera in 1975 by the company proclaimed a new era of photography. Frontiers are still widening with the invention of the smartphone [24].

The scenario of the Self-portraiture drastically changes when self-portrait is introduced to Photographic technologies. At a glance, the change of the medium appears discreet, like before, only a segment of the self-portraiture comprise a visible indication to the medium. In that situation, only characteristics of the profession are merely altered to suit the new medium: the traditional painting brushed has transformed into the camera [25], so that self-reflective node is reduced just imagery. The change brought about by photography goes further. On the one hand, the automatic inscription of visual realism on the image-sensitive film expresses the artist's intentions and loosens the selfportrait's relationship to self-production [26]. The portrayed person's operation of the shutter release is no longer considered compulsory. Making a photographic self-portrait is not so much a case of looking at oneself - or, more specifically, an "intermediate visual image" of oneself (Wilson 2012) - but one of manipulating the picture by posing, conceiving the composition, and - again deciding to mark a photo as a self-portraiture. In the same vein, Martin Parr attaches the title autoportrait to a photo book that collects portraits that professional photographers have taken on behalf of Parr in tourist spots around the globe [27]. On the other hand, Ilse Bing's Self-Portrait with Leica from 1931, 20 uses the mechanical image production of photography with the opposite purpose. Using a refined mirror arrangement, bing succeeds in pictorially stating that the person behind the camera is shown in the image [28].

We see both the artist's eyes and the camera's "head" within the situation of Bins self-portrait: it's a kind of dual self-portrait. That understanding, which shows the camera produced a real resemblance to its actual image, acts as an assurance that it's an exact resemblance of the artist's face. At the same time, the person using the photography medium and the person are both reflected. By attaching the likeness of Bing to a photography device used to capture the self-portrait, the visual image inferred that we saw a self-portrait. In case if we don't know the person in the picture, and don't have access to the title, we can understand that we are interacting with a representation which produced jointly by the represented person and the camera. The photographic camera does not require any particular effort to express itself in the course of depicting itself. Therefore, photography is not only symbolically represented as an attribute by the lens, but the optical installation is intended to show the person in self-portrait is also the photographer to has triggered the remote shutter release of the camera. The mirror shows the direction the reflective light takes to the camera lens. An optical reflection alternative is a recurring form used by both amateur and Professional Photographers. Remarkable setups such as Bing's used, can be used without as any mirroring surface can also do the same function, can show the camera and photographer both. Incase if cameras and photographers are reflected accidentally, the effect can happen [29]. The reflective mirror allows the camera to turn its attention towards the camera and the viewer - where the picture produced and also extend the point of view to space usually has to stay outside [30].

One of the most popular ways to produce a self-timer digital self-portrait is the remote shutter release, and only the latter's reverse image has this ability [31]. It is impossible to determine if a selftimer was used or whether someone else was operating the camera, just looking at the snapshot. Also, a self-timer's mechanical system limits the "photographer's" access. The remote shutter release ostentatiously held by a person in the photo may indicate who is operating the shutter's version. Nevertheless, because for optical reasons, the cable connection to the camera can not be wholly revealed, 24 it refers to the camera not so much indexically as symbolically as an attribute again. However, as Ingrid Hölzl has stated, the remote shutter release is insufficient to create a portrait-like self-portraiture [32]. 


\subsection{Smart Phone And Contemporary Selfie}

Contemporary smartphones are intentionally designed to explore the room behind the viewfinder that had previously been covered. It combines the front-facing camera with a display that photographers can see in a live image. The self-reflected selfie helps you to monitor the picture in the way you check a mirror. The main difference is that the selfie photographer is pressing the release button, and the video mirror image eternalizes a selected moment. The resulting digital image file is laterally correct and corresponds to the one seen by an external observer or another photographer. The smartphone addresses a media-specific problem of visual self-reflexivity by art historians Hilde van Gelder and Helen Westgeest [33]. Analog photography differentiated the picture's transparency from its exposure moment. Before it can be displayed, the latent and negative image must be created and converted into a positive image.

The image's instant availability allows the selfie scene and its counterpart to appear together in the same image on display. This synchronization of the stage and its resulting image supports the selfie's equation with the "mirror with a memory." The subsequent practices of editing, contextualizing, publishing, or sharing the photographs cannot be easily captured in the same image as the photography medium is designed to achieve one moment in time. As a result, such activities make the selfie-taking genre a unique photography artifact with a contemporary approach.

Selfies make the study of what people in a photograph want to look like because they show people in control of the exposure. Selfies give themselves to different readings of self-reflexivity: they can be viewed as individual self-reflections, they can be seen to reflect certain aspects of the photographic medium and its practice, and finally, these two reflections can be combined, and the selfie scene agent can be understood as composed of human and technological aspects.

\section{Conclusion}

Throughout the known history of humanity, Self-image always gets immense attention as humans' aesthetic sense got an evolution. We have explored the traces of historical evidence of surviving self-images that have evolved from eminent Rome and Greek civilizations. Self-Image history traced back to historic Egypt. The concept of self-image evolved throughout this long period. It got a significant breakthrough when the traditional camera was invented and industrialized. Again, self-image gained phenomenal prominence and growth when smartphones and the internet have connected with advanced communication networks.

Contemporary self-image has achieved many dynamic properties as it exists in the era of modern society and evolved within the progression of new technologies. During the venture of exploring the self-images in the historical and current scenario, I found its strong linkage with our internal self (identity), as well as the complexities of the digital and visual culture of contemporary society. I found that all these elements are interconnected with the fibers of all these elements of society, culture, arts, and other elements of our social ecology, which creates a sophisticated beauty, and I am lost into it.

According to McLuhan's media theory, a self-portrait's cultural value depends on the sociological scenario, where it has come into being. Culture of the selfie. In this attempt, I am going to finds the roots in ancient history and culture, elaborate its significance in current society. For this purpose, we will dig down the past from old Egyptian and Greek organizations mythological but significant selfimages to today's contemporary Selfies. Contemporary selfie embarks the latest technological advancements and dynamics of our modern society.

\section{References}

[1] A. Peraica, "Culture of the selfie: self-representation in contemporary visual culture," in Theory on Demand n.24, 2017.

[2] S. Djamasbi and A. Hall-Phillips, "Visual Search," in Eye Tracking in User Experience Design, 2014.

[3] I. Shaw, "Egypt and the outside world," in The Oxford History of Ancient Egypt, 2000.

[4] D. Laboury, "Tracking Ancient Egyptian Artists, a Problem of Methodology. The Case of the Painters of Private Tombs in the Theban Necropolis during the Eighteenth Dynasty," Art Soc. Anc. Mod. Context. ..., 2012. 
[5] R. L. Martinez and J. J. Martin, "Myths of Renaissance Individualism," Sixt. Century J., 2006, doi: $10.2307 / 20478193$.

[6] H. Stoddart, "Guide to Sustainable Development Governance," Stakehold. Forum, 2011.

[7] R. Whittemore and K. Knafl, "The integrative review: Updated methodology," Journal of Advanced Nursing. 2005, doi: 10.1111/j.1365-2648.2005.03621.x.

[8] D. M. Packwood, P. A. Brooksby, A. D. Abell, and A. J. Downard, "pH-dependent wettability of carboxyphenyl films grafted to glassy carbon," in Australian Journal of Chemistry, 2011, doi: $10.1071 / \mathrm{CH} 10285$.

[9] D. Packwood, "Socrates Becomes Narcissus: Moral Mediation and Artistic Representation in Achille Bocchi's Symbolicarum quaestionum," Humboldt-Universität zu Berlin, 2011. [Online]. Available: https://edoc.hu-berlin.de/handle/18452/8288?show=full.

[10] G. D. Williams, "Naturales quaestiones," in Brill's Companion to Seneca, 2015.

[11] V. Egan and C. McCorkindale, "Narcissism, vanity, personality and mating effort," Pers. Individ. Dif., 2007, doi: 10.1016/j.paid.2007.06.034.

[12] G. Rosenthal, "Economic and Social Council," in The Oxford Handbook on the United Nations, 2009.

[13] A. David, “Khan Academy!,” Prim. Teach. Updat., 2011, doi: 10.12968/prtu.2011.1.2.52a.

[14] N. Bostrom, "A History of Transhumanist Thought," J. Evol. Technol., 2005.

[15] M. H. Rodrigues, "Albrecht Durer and the 16TH Century Melancholy," Int. Vis. Cult. Rev., 2020, doi: 10.37467/gka-visualrev.v2.2547.

[16] "Khan Academy," Choice Rev. Online, 2011, doi: 10.5860/choice.48-2433.

[17] J. L. Koerner, "Factura," Res Anthropol. Aesthet., 1999, doi: 10.1086/resv36n1ms20167473.

[18] D. V. P. and P. S. D. P. J. Naik, "Pelagia Research Library,” Der Chem. Sin., 2013.

[19] British Library, "Quantitative Methods in Social Research," Social Science Collection Guides. 2008.

[20] "Interview with Zhang Nuanxin," Camera Obs. Fem. Cult. Media Stud., 1988, doi: 10.1215/027053466-3_18-20.

[21] J. Beloff, "Readings in philosophy of psychology," Behav. Res. Ther., 1982, doi: 10.1016/00057967(82)90043-2.

[22] S. Napier, Miyazakiworld: A Life in Art. 2018.

[23] D. Collins, The story of Kodak. 1990.

[24] S. Anthony, "Kodak’s Downfall Wasn't About Technology,” Harv. Bus. Rev., 2016.

[25] Z. Zhang, "A flexible new technique for camera calibration," IEEE Trans. Pattern Anal. Mach. Intell., 2000, doi: 10.1109/34.888718.

[26] D. Bate, “Art Photography,” Photogr. Key Concepts, 2009.

[27] R. Howells, "Self Portrait: The Sense of Self in British Documentary Photography," Natl. Identities, 2002, doi: 10.1080/14608940220143808.

[28] M. Lister, The Photographic Image in Digital Culture. 2013.

[29] G. DOY, “ART PHOTOGRAPHY NOW,” Art B., 2006, doi: 10.1111/j.1467-8357.2006.00680_1.x.

[30] A. Linkman, "History of Photography Taken from life: Post-mortem portraiture in Britain 1860-1910 Taken from Life: Post-Mortem Portraiture in Britain 1860-1910," Acta Hist. Artium Acad. Sci. Hungaricae Hist. Photogr., 2006, doi: 10.1080/03087298.2006.10443484.

[31] I. Hölzl, "Editorial: Photography and Movement," History of Photography. 2011, doi: 10.1080/03087298.2010.496219.

[32] I. Hölzl and I. Hölzl, "Fotografisches Selbstporträt als Doppelter Index," in Der autoporträtistische Pakt, 2019. 
[33] G. van Hilde and H. Westgeest, "Photography and painting in multi-mediating pictures," Vis. Stud., 2009, doi: 10.1080/14725860903106120.

[34] A. Streitberger and H. van Gelder, "Photo-filmic images in contemporary visual culture," Philos. Photogr., 2010, doi: 10.1386/pop.1.1.48/7. 